
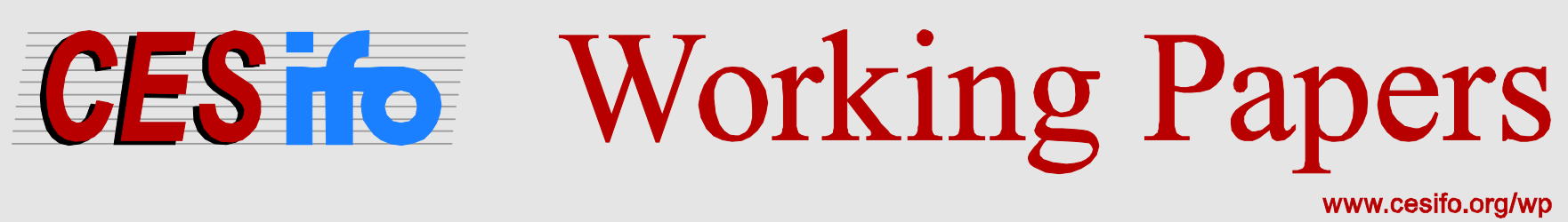

\title{
Youth Unemployment in Europe: Persistence and Macroeconomic Determinants
}

\author{
Guglielmo Maria Caporale \\ Luis Gil-Alana
}

CESIFO WORKING PAPER NO. 4696

CATEGORY 4: LABOUR MARKETS

MARCH 2014
An electronic version of the paper may be downloaded
- from the SSRN website:
- from the RePEc website:
- from the CESifo website:
WwW.SSRN.com
www.RePEc.org
www.CESifo-group.org/wp

\section{CESifo}




\title{
Youth Unemployment in Europe: Persistence and Macroeconomic Determinants
}

\begin{abstract}
This paper investigates the statistical features and the macroeconomic determinants of youth unemployment in a number of European countries. First, it explores its short and long memory properties by estimating both autoregressive and fractional integration models. This type of analysis sheds light on the degree of persistence of the series, and on whether policy actions are required for highly persistent series. Second, it investigates the main determinants of youth unemployment in Europe by estimating fractional cointegration models. The evidence suggests that this series is highly persistent in all the countries examined, and that in some of them there is a statistically significant long-run equilibrium relationship linking it to macroeconomic variables such as GDP and inflation.
\end{abstract}

JEL-Code: C220, C320, J640.

Keywords: youth unemployment, fractional integration, fractional cointegration.

\author{
Guglielmo Maria Caporale* \\ Department of Economics and Finance \& \\ Centre for Empirical Finance \\ Brunel University \\ United Kingdom - London, UB8 3PH \\ Guglielmo-Maria.Caporale@brunel.ac.uk
}

\author{
Luis Gil-Alana \\ University of Navarra \\ Pamplona / Spain \\ alana@unav.es
}

*corresponding author

February 2014

We are grateful to Misbah Tanveer Choudhry, Enrico Marelli and Marcello Signorelli for kindly supplying the dataset. The first-named author gratefully acknowledges financial support from a Marie Curie International Research Staff Exchange Scheme Fellowship within the 7th European Community Framework Programme under the project IRSES GA-2010269134, and the second-named author from the Ministry of Economy of Spain (ECO20112014 ECON Y FINANZAS, Spain. 


\section{Introduction}

Youth unemployment has attracted significant attention in recent years, especially in Europe, where it is particularly high relative to adult unemployment (see, e.g., Perugini and Signorelli, 2010), and has been affected even more than the latter by financial crises (see Choudhry et al., 2012a). Some key factors driving it that have been identified include the relatively low human capital of young people (see OECD, 2005), the "youth experience gap” (see Caroleo and Pastore, 2007), and the mismatch between the skills acquired through education and those required by employers (see, e.g., Quintini et al., 2007). Policy recommendations have been put forward both in the academic literature (see, e.g., Brunello et al., 2007) and by the European Commission (2008).

This paper investigates the main statistical features and the macroeconomic determinants of youth unemployment in a number of European countries. It is well known that an important feature of unemployment in Europe is itsrelatively high degree of persistence, which suggests that a hysteresis model (Blanchard and Summers, 1986, Gordons, 1988) might be appropriate. This appears to be a feature also of European youth unemployment (see, e.g., Heckman and Borjas, 1980, Ryan, 2001, and Caporale and GilAlana, 2013). Therefore, first of all we examinethe degree of persistence of the series (which sheds light on whether appropriate policy actions are required for highly persistent series)by estimating both autoregressive AR(1) processes and long memory (fractional integration) models. Second, we investigate the main macroeconomic determinants of youth unemployment in Europe by means of a fractional cointegrationmodels including variables such as GDP and inflationpossibly explaining its behaviour. The layout of the paper is as follows. Section 2 outlines the econometric framework. Section 3 presents the data and the empirical results. Section 4 offers some concluding remarks. 


\section{The econometric framework}

As mentioned in the introduction, our main analysis is based on the concept of fractional integration, which allows the differencing parameter d making a series stationary I(0) to be a fraction as well as an integer. Therefore, the series of interest can be represented as

$$
(1-L)^{d} x_{t}=u_{t}, \quad t=0, \pm 1, \ldots
$$

whereu $\mathrm{t}_{\mathrm{t}}$ is assumed to be an $\mathrm{I}(0)$ process, defined as a covariance stationary process with a bounded positive spectral density function. Note that this approach includes the unit root case as a particular case when $\mathrm{d}=1$.

Given the above parameterisation, one can consider different cases depending on the value of $d$. Specifically, if $d=0, \mathrm{x}_{\mathrm{t}}=\mathrm{u}_{\mathrm{t}}, \mathrm{x}_{\mathrm{t}}$ is said to be a "short memory" or $\mathrm{I}(0)$ process, and in the case of autocorrelated (AR) disturbances the autocorrelation is "weak", i.e. the autocorrelation function decays at an exponential rate; if $d>0, x_{t}$ is said to be a "long memory" process, so called because of the strong association between observations far apart in time. In this case, if $d$ belongs to the interval $(0,0.5) \mathrm{x}_{\mathrm{t}}$ is still covariance stationary, while $d \geq 0.5$ implies nonstationarity. Finally, if $d<1$, the series is mean-reverting, with the effects of shocks disappearing in the long run, in contrast to the case with $d \geq 1$ when these persist forever.

Two methods of estimation of the fractional differencing parameter are employed here: one is a Whittle parametric approach in the frequency domain (Dahlhaus, 1989), while the other is a semiparametric "local" Whittle method (Robinson, 1995; Abadir et al., 2007). In addition, a simple AR(1) model is also considered as an alternative to measure persistence as the autoregressive coefficient. Other more general $\operatorname{AR}(p)$ processes could be considered, with persistence then being defined as the sum of the AR 
coefficients. However, given the relatively small sample size in our case, a simple AR(1) specification is adequate to describe the short-run dynamics of the series.

The fractional integration framework can be extended to the multivariate case by estimating a fractional cointegration model. Specifically, we follow the approach developed in Gil-Alana (2003), which is a natural generalisation of the Engle and Granger’s (1987) procedure allowing for fractional parameters. In particular, we estimate a linear regression of youth unemployment against its macroeconomic determinants, and check the significance of the estimated coefficients as well as the order of integration of the residuals; if this is smaller than for the individual series, then cointegrationholds and there exists a long-run equilibrium relationship between the variables which can be interpreted as the steady state in economic terms. In addition, a Hausman test for the null of no cointegration against the alternative of fractional cointegration, as suggested by Marinucci and Robinson (2001) is also carried out.

\section{Empirical results}

The dataset used includes the total youth unemployment rate in 15 countries, namely Austria, Belgium, Denmark, Finland, France, Greece, Ireland, Italy, Luxembourg, the Netherlands, Norway, Portugal, Spain, Sweden, and the United Kingdom. This variable is defined as the number of unemployed in the 15-24 years age group divided by the labour force for that group, and has been obtained from the International Labor Organisation (ILO).For GDP and inflation,output and consumer price series from the World Development Indicators are used. All series are annual and span the period from 1980 to 2005. 
As a preliminary step we estimate a simple AR(1) process to measure the persistence of the series as its $\operatorname{AR}(1)$ coefficient. The results for the three series are displayed in Table 1.

\section{[Insert Table 1 about here]}

It can be seen that the autoregressive coefficients are much higher for youth unemployment and inflation compared to GDP. In the case of youth unemployment, the highest values are found for the peripheral (Northern and Southern) countries: Ireland (0.94), Finland (0.92), the Netherlands (0.89), Spain (0.89), Norway (0.88), Sweden (0.88), Italy (0.87) and Greece (0.86). This high level of persistence is consistent with the empirical evidence on total unemployment in most European countries, suggesting the relevance of hysteresis models in the European case (see, e.g., Gordon, 1989, Graafland, 1991, Lopez et al., 1996).

Next, we estimate the fractional differencing parameter $d$ and the corresponding 95\% intervals for each of the three series (youth unemployment, inflation and GDP) in each country using the parametric approach based on the Whittle function in the frequency domain. In all cases, an intercept is included in the model and the ddifferenced process is assumed to be a white noise process. We report in bold in Table 2 the cases where the unit root null (i.e., $d=1$ ) cannot be rejected.

\section{[Insert Table 2 about here]}

This happens in five countries (UK, Italy, Norway, Sweden and Ireland) for all three series. In the case of youth unemployment, rejections of the null (in favour of higher degrees of integration) only occur for Finland, the Netherlands, Portugal and Spain (the latter two countries having some of the highest youth unemployment rates in the sample). For inflation, the unit root null cannot be rejected in any case. For GDP, this hypothesis is rejected in favour of explosive behaviour $(\mathrm{d}>1)$ in Finland, the Netherlands, Portugal 
and Spain, whilst evidence of mean reversion $(\mathrm{d}<1)$ is found for Austria, Belgium, Denmark, France, Greece and Luxembourg.

\section{[Insert Table 3 about here]}

Table 3 focuses on the semiparametric results using three different bandwidth parameters. For each series there is at least one case when the unit root null cannot be rejected. Given the evidence of nonstationarity, the estimation was carried out using first differences, then adding one to the estimated values to obtain the integration orders. Overall, this evidence suggests nonstationarity and the presence of a unit root in all three series in all countries examined.

The following step is the estimation of a multivariate (cointegration) model. We started by including the same set of variables as in previous studies such as Jacobsen (1999), Blanchflower and Freeman (2000), Choudhry et al. (2012a). In particular, there is a large literature emphasising the impact of output (growth) on unemployment (the socalled Okun's law - see for example Lee, 2000, and Solow, 2000). Also, it appears that youth unemployment is even more sensitive to macroeconomic (and labour market) conditions than total unemployment (see Choudhry et al., 2012b). However, since regressors such as FDI and openness were found not to be significant, the results reported below are those obtained from a model including GDP and inflation only as the macroeconomic determinants of youth unemployment, namely

$$
\mathrm{y}_{\mathrm{t}}=\alpha+\beta \mathrm{x}_{1 \mathrm{t}}+\mathrm{x}_{2 \mathrm{t}}+\mathrm{x}_{\mathrm{t}} ; \quad(1-\mathrm{L})^{\mathrm{d}} \mathrm{x}_{\mathrm{t}}=\mathrm{u}_{\mathrm{t}}, \quad \mathrm{t}=1,2, \ldots,
$$

where $\mathrm{y}_{\mathrm{t}}$ stands for the youth unemployment rate, $\mathrm{x}_{1 \mathrm{t}}$ for inflation and $\mathrm{x}_{2 \mathrm{t}}$ for GDP. The error term $\mathrm{u}_{\mathrm{t}}$ is assumed to be a white noise or have an autocorrelated structure in Table 4 and 5 respectively.

\section{[Insert Table 4 about here]}


Table 4 shows that for six countries (Italy, Belgium, Denmark, France, Greece and Luxembourg)the estimated value of $d$ is smaller than 1 ; however, in all these cases the confidence intervals are so wide that the unit root null cannot be rejected. In fact, the only rejections of the unit root null occur in the cases of Finland, the Netherlands, Portugal and Spain, but always in favour of higher orders of integration. ${ }^{1}$ Therefore, there is no evidence of cointegration of any degree under the assumption of uncorrelated errors. As for the estimated coefficients, they are all negative and more significant for inflation than GDP.

\section{[Insert Table 4 about here]}

Next, we analyse the case with autocorrelated disturbances. Specifically, we consider a simple AR(1) process, the reason being that, given the small number of observations, higher orders would lead to overparameterised models. In this case all the estimated values of $d$ are below 1 and close to 0 in many cases, implying mean-reversion and therefore cointegration. The low fractional differencing parameter is now combined with a very large AR coefficient, implying that the errors are still very persistent. Only for Finland is d significantly above 0 . As for the estimated coefficients, the inflation one is significant and negative in all cases except Spain, whilst the GDP one is significant in half of the cases. Given the differences in the results depending on the specification of the error term, we also estimated d in equation (6) using a log-periodogram semiparametric estimator. These additional results (not reported) suggest that the differencing parameter is very sensitive to the bandwidth parameter, although in most cases lies in the interval between 0.5 and 1, implying fractional integration, nonstationarity and mean-reverting behaviour.

\footnotetext{
${ }^{1}$ These countries also display orders of integration above 1 in the univariate analysis.
} 
Finally, we perform the Hausman test proposed by Marinucci and Robinson (2001). This is specified as follows:

$$
\mathrm{H}_{\mathrm{is}}=8 \mathrm{~s}\left(\hat{\mathrm{d}}^{*}-\hat{\mathrm{d}}_{\mathrm{i}}\right)^{2} \rightarrow_{\mathrm{d}} \chi_{1}^{2} \quad \frac{1}{\mathrm{~s}}+\frac{\mathrm{s}}{\mathrm{T}} \rightarrow 0,
$$

where $\mathrm{i}=\mathrm{x}, \mathrm{y}$ and zstands for each of the series under examination (youth unemployment, inflation and GDP) in turn, $\mathrm{s}$ is the bandwidth parameter (we set $\mathrm{s}=$ $\left.(T)^{0.5}\right), \hat{d}_{i}$ are the univariate estimates of the parent series, and $\hat{d}^{*}$ is a restricted estimate obtained in the multivariate representation under the assumption that $d_{x}=d_{y}=d_{z}$. The results using this approach are displayed in Table 6.

\section{[Insert Table 6 about here]}

The test statistics indicate the presence of fractional cointegration in seven out of the fifteen countries examined, with statistical significance for youth unemployment and inflation in the majority of cases. It is also noteworthy that the estimated order of integration in the cointegrating regression is in the interval $(0.5,1)$ in all cases, implying nonstationary mean-reverting behaviour. The highest degree of cointegration is found in the case of Italy and Portugal, where the estimated $d$ is equal to 0.576 and 0.577 respectively, followed by the UK (0.634), Luxembourg (0.646), the Netherlands (0.746), Ireland (0.771) and Sweden (0.810). For the remaining countries, this approach provides no evidence of cointegration.

\section{Conclusions}

Both academics and policy makers have recently focused on the challenge represented by European youth unemployment, which has become even higher relative to adult unemployment following the recent financial crisis and appears to be very persistent. This 
paper has investigated its stochastic properties as well as its macroeconomic determinants by using annual data on total youth unemployment in 15 countries and estimating autoregressive and long memory (fractionally integrated) models as well as fractional cointegration ones. The evidence confirms that youth unemployment is highly persistent in all European countries examined, which suggests the relevance of hysteresis models (Blanchard and Summers, 1986, Gordon, 1988) in a European context and the need for active labour market policies aimed at preventing short-term unemployment from becoming structural (long-term). These could include better "school-to-work transition" institutions as well as educational, placement and training schemes (see Choudhry et al., 2012a).

As for the macroeconomic factors driving European youth unemployment, the fractional cointegration results are rather sensitive to the method applied. Specifically, when following the approach of Gil-Alana (2003), the findings are different depending on the underlying assumptions about the error term: if the errors are assumed to be uncorrelated, no evidence of cointegration is found in any case; by contrast, under the assumption of autocorrelated errors, cointegration appears to hold in all cases. When using the semiparametric method of Marinucci and Robinson (2001) some evidence of (fractional) cointegration is obtained in some cases with its estimated order in the interval $(0.5,1)$. A plausible explanation for the sensitivity of the results to the method employed is the relatively small size of the sample used.

Nevertheless, the analysis provides some useful evidence on the existence of longrun relationships between youth unemployment in Europe and two key macroeconomic determinants, namely GDP and inflation. It confirms in particular the importance of the linkage between output (growth) and unemployment (the so-called Okun's law), and the sensitivity of youth unemployment (even more than total unemployment) to overall 
macroeconomic conditions (see Choudhry et al., 2012b). Of course a key role is also played by macroeconomic (as well as labour market) policies and institutions, as, for instance, stressed by the OECD (2006), but recommending the specific actions required to address the so-called "euro-sclerosis" (or poor employment performance of most European countries) is an issue beyond the scope of the present study, whose aim is simply to offer some evidence on the persistence of youth unemployment in Europe and its relationship with output and inflation. 


\section{References}

Abadir, K.M., W. Distaso and L. Giraitis. 2007. Nonstationarity-extended local Whittle estimation. Journal of Econometrics 141: 1353-84.

Blanchard, O.J. and L.H. Summers, 1986, Hysteresis and the European unemployment problem, in NBER Macroeconomics Annual (Ed.) S. Fischer, MIT Press, Cambridge, Vol. 1., 15-78.

Blanchflower, D.G. and R. Freeman (2000), Youth Unemployment and Joblessness, University of Chicago Press, Chicago, IL.

Brunello, G., Garibaldi, P. and E. Wasmer (2007), Education and Training in Europe, Oxford University Press, New York, NY.

Caporale, G.M. and L.A. Gil-Alana (2013), "Persistence in youth unemployment”, Empirical Economics Letters, 12, 3, 319-325.

Caroleo, F.E. and F. Pastore (2007), “The youth experience gap: explaining differences across EU countries”, no. 41, Quaderni del Dipartimento di Economia, Finanza e Statistica, Universita’ di Perugia, Perugia.

Choudhry, M.T., Marelli, E. and M. Signorelli (2012a), "Youth unemployment rate and impact of financial crises”, International Journal of Manpower, 33, 1, 76-95.

Choudhry, M.T., Marelli, E. and M. Signorelli (2012b), "Youth and total unemployment rate: the impact of policy and institutions”, mimeo, Department of Economics and Management, University of Brescia.

Dahlhaus, R., 1989, Efficient parameter estimation for self-similar process. Annals of Statistics 17, 1749-1766.

Engle, R.F. \& Granger, C.W.J. (1987) Cointegration and error correction: representation, estimation, and testing, Econometrica, 55, pp. 251-276. 
European Commission (2008), Employment in Europe, ch.5, European Commission, Luxembourg.

Fuhrer, J. and G. Moore (1995), Inflation persistence, Quarterly Journal of Economics 110, 127-159.

Gil-Alana, L.A., 2003, Testing of fractional cointegration in macroeconomic time series, Oxford Bulletin of Economics and Statistics 65, 4, 517-529.

Gordon, R.J., 1988, Back to the future. European unemployment today viewed from America in 1939, Brooking Papers on Economic Activity 19, 1271-1232.

Gordon, R.J., 1989. Hysteresis in history. Was there ever a Phillips curve? American Economic Review, Papers and Proceedings, 79, 220-225.

Graafland, J.J., 1991, “On the causes of hysteresis in long term unemployment in the Netherlands”, Oxford Bulletin of Economics and Statistics, 53, 2, 155-170.

Heckman, J.J. and G.J. Borjas (1980), “Does unemployment cause future unemployment? Definitions, questions and answers from a continuous time model of heterogeneity and state dependence”, Economica, 47, 187, 247-283.

Jacobsen, J.P. (1999), “Labor force participation”, Quarterly Review of Economics and Finance, 39, 5, 597-610.

Lee, J. (2000), “The robustness of Okun’s law: evidence from OECD countries”, Journal of Macroeconomics, 22, 2, 331-356.

Lopez, H., E. Ortega and A. Ubide, 1996. Explaining the dynamics of Spanish unemployment, Working Paper in Economics, no.96/14, European University Institute. Marinucci, D. and P.M. Robinson (2001) Semiparametric fractional cointegration analysis, Journal of Econometrics 105, 225-247.

Nelson, C.R. and C.I. Plosser (1982), Trends and random walks in macroeconomic time series.Some evidence and implications, Journal of Monetary Economics 10, 139-162. 
OECD (2005), Education at Glance, Paris.

OECD (2006), Employment Outlook, Paris.

Perugini, C. and M. Signorelli (2010), "Youth labour market performance in European regions”, Economic Change and Restructuring, 43, 2, 151-185.

Quintini, G., Martin, J.P. and S. Marti (2007), “The changing nature of the school-towork transition process in OECD countries”, DP no. 2582, Institute for Study of Labor, IZA, Bonn.

Robinson, P. M. (1995), Gaussian semi-parametric estimation of long range dependence, Annals of Statictics 23, 1630-1661.

Ryan, P. (2001), “The school-to-work transition: a cross-national perspective”, Journal of Economic Literature, 39, 1, 34-92.

Solow, R.M, (2000), "Who is hit hardest during a financial crisis? The vulnetaribility of young men and women to unemployment in an economic downturn”, IZA Discussion Papers, 4359. 
Table 1: Estimated AR coefficients for each series in each country

\begin{tabular}{|c|c|c|c|}
\hline Country & Youth unemploym. & Inflation & GDP \\
\hline UNITED KINGDOM & 0.838 & 0.683 & 0.586 \\
\hline ITALY & 0.872 & 0.978 & 0.443 \\
\hline AUSTRIA & 0.848 & 0.607 & 0.194 \\
\hline BELGIUM & 0.715 & 0.765 & 0.061 \\
\hline DENMARK & 0.605 & 0.876 & 0.173 \\
\hline FINLAND & 0.925 & 0.935 & 0.608 \\
\hline FRANCE & 0.763 & 0.969 & 0.345 \\
\hline GREECE & 0.866 & 0.937 & 0.488 \\
\hline IRELAND & 0.940 & 0.764 & 0.567 \\
\hline LUXEMBOURG & 0.795 & 0.697 & 0.112 \\
\hline NETHERLANDS & 0.893 & 0.791 & 0.648 \\
\hline NORWAY & 0.888 & 0.908 & 0.487 \\
\hline PORTUGAL & 0.839 & 0.929 & 0.639 \\
\hline SPAIN & 0.892 & 0.963 & 0.626 \\
\hline SWEDEN & 0.885 & 0.849 & 0.434 \\
\hline
\end{tabular}


Table 2: Estimatesof $d$ and $95 \%$ confidence intervals for the individual series

\begin{tabular}{|c|c|c|c|}
\hline Country & Youth unemployment & Inflation & GDP \\
\hline UNITED KINGDOM & $1.37 \quad(0.31,2.10)$ & $0.53(0.31,1.35)$ & $0.72(0.02,1.61)$ \\
\hline ITALY & $1.15(0.94,1.45)$ & $1.43(0.47,1.83)$ & $0.29 \quad(-0.07,1.10)$ \\
\hline AUSTRIA & $1.09(0.71,1.50)$ & $0.44 \quad(0.12,1.02)$ & $0.08 \quad(-0.30,0.57)$ \\
\hline BELGIUM & $0.81 \quad(0.31,1.31)$ & $0.97 \quad(0.01,1.54)$ & $-0.15 \quad(-0.62, \quad 0.39)$ \\
\hline DENMARK & $0.59 \quad(0.27,1.35)$ & $0.25 \quad(-0.08,1.12)$ & $0.05 \quad(-0.34,0.55)$ \\
\hline FINLAND & $1.96(1.31,2.72)$ & $1.02(0.49,1.58)$ & $0.72(0.19,1.46)$ \\
\hline FRANCE & $1.09(0.44,1.61)$ & $1.33(1.00,1.67)$ & $0.23(-0.24,0.80)$ \\
\hline GREECE & $1.01(0.42,1.52)$ & $0.72(0.55,1.27)$ & $0.26(0.04,0.53)$ \\
\hline IRELAND & $1.29(0.92,1.84)$ & $0.97 \quad(0.10,1.47)$ & $0.47(0.24,1.05)$ \\
\hline LUXEMBOURG & $1.16(0.28,1.76)$ & $1.26(-0.14,1.88)$ & $0.05 \quad(-0.34,0.47)$ \\
\hline THE NETHERLANDS & $1.76(1.31,2.25)$ & $1.08(0.42,1.60)$ & $0.91(0.42,1.68)$ \\
\hline NORWAY & $1.41(0.78,2.16)$ & $0.72(0.49,1.29)$ & $0.41(-0.11,1.84)$ \\
\hline PORTUGAL & $1.69(1.10,2.32)$ & $1.31 \quad(0.77,2.14)$ & $0.81(0.24,1.46)$ \\
\hline SPAIN & $1.62(1.19,2.14)$ & $0.99(0.65,1.37)$ & $0.78 \quad(0.34,1.37)$ \\
\hline SWEDEN & $1.33(0.91,1.92)$ & $0.51 \quad(0.33,1.06)$ & $0.33(-0.04,1.04)$ \\
\hline
\end{tabular}

In bold: Evidence of unit roots $(d=1)$ at the $5 \%$ level. 
Table 3: Estimates of $d$ based on a local Whittle semiparametric method

\begin{tabular}{|c|c|c|c|c|c|c|c|c|c|}
\hline Country & \multicolumn{2}{|c|}{ Youth unemployment } & \multicolumn{3}{|c|}{ Inflation } & \multicolumn{3}{c|}{ GDP } \\
\hline & 4 & 5 & 6 & 4 & 5 & 6 & 4 & 5 & 6 \\
\hline U. K. & $\mathbf{0 . 7 0 1}$ & $\mathbf{1 . 1 6 9}$ & 1.453 & $\mathbf{0 . 7 6 2}$ & $\mathbf{1 . 0 0 4}$ & $\mathbf{0 . 7 7 0}$ & $\mathbf{0 . 7 3 3}$ & $\mathbf{0 . 8 8 9}$ & $\mathbf{1 . 1 6 6}$ \\
\hline ITALY & $\mathbf{1 . 3 8 6}$ & 1,500 & 1.363 & 1.423 & 1.500 & 1.500 & $\mathbf{1 . 1 3 7}$ & 0.511 & 0.572 \\
\hline AUSTRIA & $\mathbf{0 . 9 3 2}$ & $\mathbf{0 . 9 6 5}$ & $\mathbf{1 . 2 2 0}$ & $\mathbf{1 . 0 7 8}$ & $\mathbf{0 . 6 6 9}$ & 0.645 & 0.500 & 0.521 & $\mathbf{0 . 6 6 8}$ \\
\hline BELGIUM & $\mathbf{0 . 9 2 6}$ & $\mathbf{0 . 9 5 5}$ & $\mathbf{1 . 1 7 1}$ & $\mathbf{0 . 7 1 9}$ & $\mathbf{0 . 9 2 5}$ & $\mathbf{1 . 0 5 2}$ & $\mathbf{0 . 5 8 8}$ & $\mathbf{0 . 6 6 4}$ & 0.563 \\
\hline DENMARK & $\mathbf{0 . 9 0 1}$ & $\mathbf{1 . 2 0 8}$ & $\mathbf{0 . 8 0 6}$ & $\mathbf{0 . 8 9 9}$ & $\mathbf{0 . 8 8 1}$ & $\mathbf{1 . 0 7 7}$ & $\mathbf{0 . 5 9 8}$ & 0.534 & $\mathbf{0 . 7 1 0}$ \\
\hline FINLAND & $\mathbf{1 . 0 9 5}$ & 1.388 & 1.500 & $\mathbf{0 . 8 3 8}$ & $\mathbf{1 . 1 9 8}$ & $\mathbf{1 . 0 8 4}$ & 0.500 & $\mathbf{0 . 7 8 2}$ & $\mathbf{1 . 0 0 8}$ \\
\hline FRANCE & $\mathbf{1 . 4 0 8}$ & $\mathbf{1 . 1 4 9}$ & 1.393 & $\mathbf{1 . 2 2 0}$ & 1.500 & 1.500 & 0.500 & $\mathbf{0 . 8 8 2}$ & 0.524 \\
\hline GREECE & 0.500 & 0.605 & $\mathbf{0 . 8 7 8}$ & 0.500 & 0.517 & $\mathbf{0 . 7 3 0}$ & 0.500 & $\mathbf{0 . 7 0 1}$ & 0.500 \\
\hline IRELAND & $\mathbf{1 . 1 7 4}$ & $\mathbf{1 . 3 3 5}$ & 1.500 & 1.500 & 1.455 & $\mathbf{1 . 1 9 4}$ & $\mathbf{0 . 7 2 5}$ & $\mathbf{0 . 9 5 8}$ & 0.569 \\
\hline LUXEMBOURG & $\mathbf{1 . 1 6 3}$ & $\mathbf{1 . 2 9 4}$ & $\mathbf{1 . 2 6 1}$ & $\mathbf{0 . 9 1 5}$ & $\mathbf{1 . 1 3 1}$ & $\mathbf{1 . 2 5 6}$ & 0.500 & $\mathbf{0 . 9 3 4}$ & $\mathbf{1 . 1 0 0}$ \\
\hline NETHERLANDS & $\mathbf{1 . 2 2 2}$ & 1.500 & 1.500 & 1.430 & 1.500 & $\mathbf{1 . 1 7 8}$ & $\mathbf{0 . 6 6 4}$ & $\mathbf{0 . 6 8 2}$ & $\mathbf{0 . 9 2 8}$ \\
\hline NORWAY & 0.582 & $\mathbf{0 . 6 5 5}$ & $\mathbf{0 . 9 9 6}$ & 0.500 & $\mathbf{0 . 7 7 4}$ & $\mathbf{0 . 7 8 5}$ & 0.505 & 0.500 & $\mathbf{0 . 7 8 8}$ \\
\hline PORTUGAL & $\mathbf{0 . 5 9 2}$ & $\mathbf{1 . 1 5 9}$ & 1.455 & $\mathbf{0 . 6 7 8}$ & $\mathbf{0 . 9 0 7}$ & $\mathbf{1 . 1 4 1}$ & $\mathbf{0 . 7 6 5}$ & $\mathbf{0 . 9 9 4}$ & $\mathbf{1 . 2 3 8}$ \\
\hline SPAIN & 0.507 & $\mathbf{1 . 1 8 9}$ & 1.500 & 1.487 & $\mathbf{1 . 0 1 9}$ & $\mathbf{1 . 1 8 8}$ & 0.500 & $\mathbf{0 . 9 9 9}$ & $\mathbf{0 . 8 6 4}$ \\
\hline SWEDEN & $\mathbf{0 . 6 3 7}$ & $\mathbf{1 . 1 9 9}$ & 1.421 & $\mathbf{0 . 7 4 8}$ & $\mathbf{0 . 8 0 2}$ & $\mathbf{0 . 7 7 7}$ & $\mathbf{0 . 6 1 2}$ & $\mathbf{0 . 6 4 1}$ & 0.507 \\
\hline Lower I(1) interval & 0.588 & 0.632 & 0.664 & 0.588 & 0.632 & 0.664 & 0.588 & 0.632 & 0.664 \\
\hline Upper I(1) interval & 1.411 & 1.367 & 1.335 & 1.411 & 1.367 & 1.335 & 1.411 & 1.367 & 1.335 \\
\hline
\end{tabular}


Table 4: Parameter estimates in the cointegrating relationship with uncorrelated errors

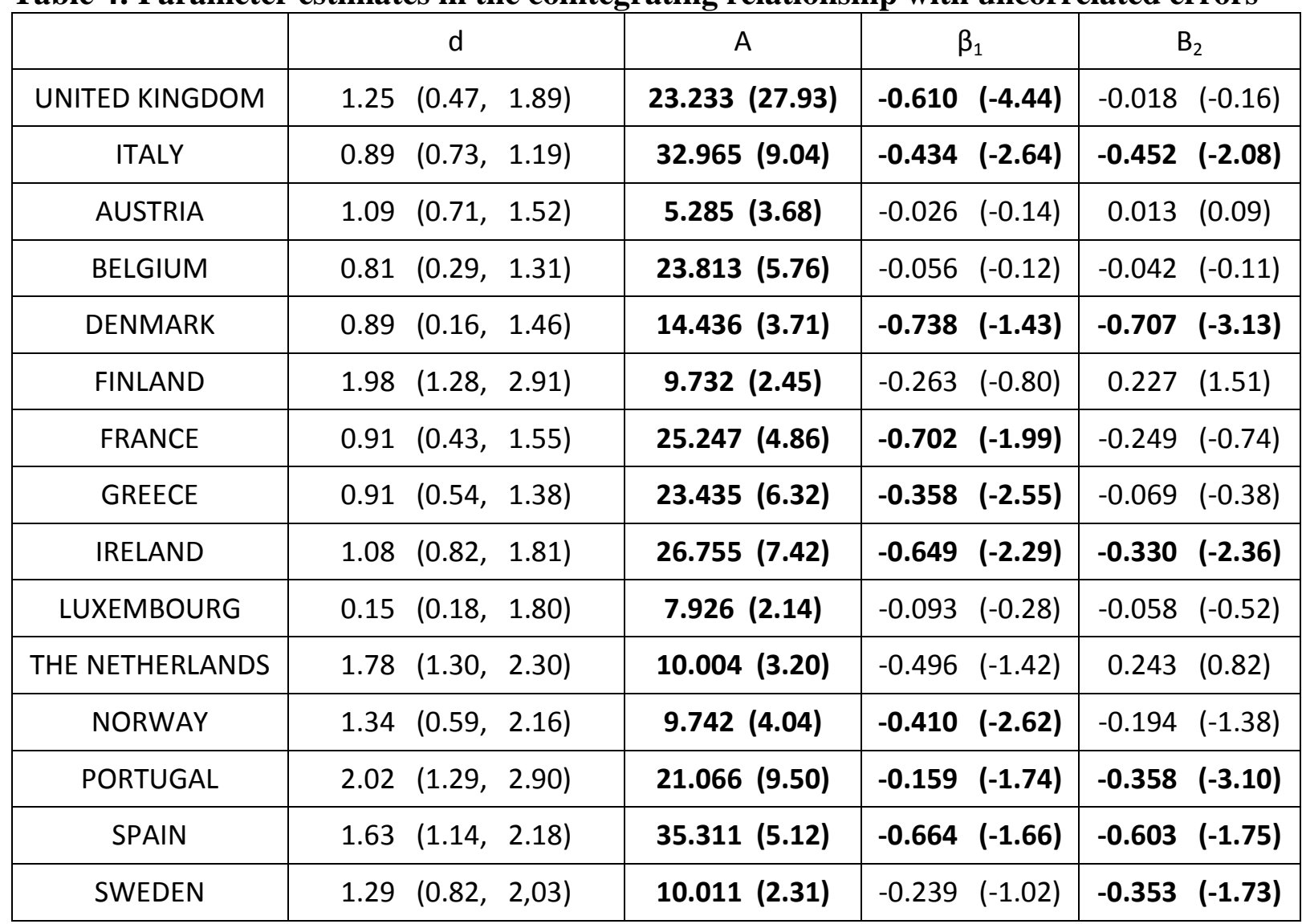

In bold, significant coefficients at the $5 \%$ level. 
Table 5: Parameter estimates in the cointegrating relationship with autocorrelated errors

\begin{tabular}{|c|c|c|c|c|c|}
\hline & d & $\alpha$ & $\beta_{1}$ & $\mathrm{~B}_{2}$ & AR \\
\hline U.K. & $0.11 \quad(-0.24,0.38)$ & 44.244 (42.89) & $-0.174(-1.88)$ & 0.319 (1.49) & 0.742 \\
\hline ITALY & $0.02 \quad(-0.26,0.43)$ & $-54.025(-64.11)$ & $-0.143 \quad(-1.80)$ & 1.496 (4.69) & 0.810 \\
\hline AUSTRIA & $-0.07 \quad(-0.37,0.29)$ & 42.765 (35.134) & $-0.413(-1.85)$ & $-0.516 \quad(-1.96)$ & 0.895 \\
\hline BELGIUM & $0.01 \quad(-0.36,0.33)$ & 65.367 (4.17) & $-0.612(-1.82)$ & $0.014 \quad(0.03)$ & 0.664 \\
\hline DENMARK & $0.07 \quad(-0.36,0.29)$ & 34.287 (32709) & $-0.984 \quad(-3.75)$ & $-0.299 \quad(-1.97)$ & 0.655 \\
\hline FINLAND & $0.58 \quad(0.14,0.89)$ & $28.789(8.74)$ & $-1.272(-4.26)$ & $-0.015 \quad(-0.07)$ & 0.710 \\
\hline FRANCE & $0.10 \quad(-0.29,0.47)$ & $7.693(6.74)$ & $-0.551(-4.50)$ & $-0.312 \quad(-0.85)$ & 0.744 \\
\hline GREECE & $0.01 \quad(-0.37,0.39)$ & $-254.69(-167.89)$ & $-0.387 \quad(-4.71)$ & $-0.077 \quad(-0.28)$ & 0.863 \\
\hline IRELAND & $0.04 \quad(-0.34,0.45)$ & $122.00(50.82)$ & $-0.723 \quad(-2.04)$ & $-1.220(-4.98)$ & 0.708 \\
\hline LUXEMBOURG & $-0.04 \quad(-0.57,0.18)$ & $43.189(30.14)$ & $-0.370 \quad(-2.28)$ & $-0.470 \quad(-2.39)$ & 0.499 \\
\hline NETHERLANDS & $0.14 \quad(-0.23,0.37)$ & 39.544 (18.41) & $-0.516 \quad(-1.94)$ & $-0.134 \quad(-0.28)$ & 0.735 \\
\hline NORWAY & $0.05 \quad(-0.28,0.39)$ & 22.147 (35.38) & $-0.665 \quad(-9.68)$ & $-0.258 \quad(-1.88)$ & 0.712 \\
\hline PORTUGAL & $0.21 \quad(-0.07,0.44)$ & $1.772(1.41)$ & $-0145 \quad(-1.99)$ & $-0.214(-1.85)$ & 0.792 \\
\hline SPAIN & $0.16 \quad(-0.14,0.47)$ & $-1.679(-0.46)$ & $0.081 \quad(-0.27)$ & $-0.649 \quad(-0.96)$ & 0.931 \\
\hline SWEDEN & $-0.11 \quad(-0.22,0.41)$ & $15.842(12.34)$ & $-1.196 \quad(-8.26)$ & $-1.060 \quad(-2.90)$ & 0.736 \\
\hline
\end{tabular}

In bold, significant coefficients at the $5 \%$ level. 
Table 6: Testing the null of no cointegration with the Hausman test of Robinson and Marinucci (2001)

\begin{tabular}{|c|c|c|}
\hline UNITED KINGDOM & ITALY & AUSTRIA \\
\hline $\mathrm{H}_{\mathrm{xs}}:=11.449^{*}$ & $\mathrm{H}_{\mathrm{xs}}:=23.104^{*}$ & $\mathrm{H}_{\mathrm{xs}}:=0.025$ \\
\hline $\mathrm{H}_{\mathrm{xs}}=5.475^{*}$ & $\mathrm{H}_{\mathrm{xs}}=28.696^{*}$ & $\mathrm{H}_{\mathrm{xs}}=0.585$ \\
\hline $\mathrm{H}_{\mathrm{xs}}=2.601$ & $\mathrm{H}_{\mathrm{xs}}=0.064$ & $\mathrm{H}_{\mathrm{xs}}=2.140$ \\
\hline $\mathrm{d}=0.634$ & $\mathrm{~d}=\quad 0.576$ & $\mathrm{~d}=0.957$ \\
\hline BELGIUM & DENMARK & FINLAND \\
\hline $\mathrm{H}_{\mathrm{xs}}:=0.625$ & $\mathrm{H}_{\mathrm{xs}}:=3.387$ & $\mathrm{H}_{\mathrm{xs}}:=0.064$ \\
\hline $\mathrm{H}_{\mathrm{xs}}=0.361$ & $\mathrm{H}_{\mathrm{xs}}=0.051$ & $\mathrm{H}_{\mathrm{xs}}=0.392$ \\
\hline $\mathrm{H}_{\mathrm{xs}}=1.102$ & $\mathrm{H}_{\mathrm{xs}}=1.714$ & $\mathrm{H}_{\mathrm{xs}}=0.331$ \\
\hline $\mathrm{d}=0.830$ & $\mathrm{~d}=\quad 0.917$ & $\mathrm{~d}=1.099$ \\
\hline FRANCE & GREECE & IRELAND \\
\hline $\mathrm{H}_{\mathrm{xs}}:=0.134$ & $\mathrm{H}_{\mathrm{xs}}:=0.784$ & $\mathrm{H}_{\mathrm{xs}}:=12.678^{*}$ \\
\hline $\mathrm{H}_{\mathrm{xs}}=0.665$ & $\mathrm{H}_{\mathrm{xs}}=3.317$ & $\mathrm{H}_{\mathrm{xs}}=7.7157^{*}$ \\
\hline $\mathrm{H}_{\mathrm{xs}}=0.275$ & $\mathrm{H}_{\mathrm{xs}}=3.019$ & $\mathrm{H}_{\mathrm{xs}}=1.398$ \\
\hline $\mathrm{d}=1.091$ & $\mathrm{~d}=1.018$ & $\mathrm{~d}=\quad \mathbf{0 . 7 7 1}$ \\
\hline LUXEMBOURG & NETHERLANDS & NORWAY \\
\hline $\mathrm{H}_{\mathrm{xs}}:=16.796^{*}$ & $\mathrm{H}_{\mathrm{xs}}:=9.063^{*}$ & $\mathrm{H}_{\mathrm{xs}}:=0.108$ \\
\hline $\mathrm{H}_{\mathrm{xs}}=9.409^{*}$ & $\mathrm{H}_{\mathrm{xS}}=7.464^{*}$ & $\mathrm{H}_{\mathrm{xs}}=2.766$ \\
\hline $\mathrm{H}_{\mathrm{xs}}=3.317$ & $\mathrm{H}_{\mathrm{xs}}=1.324$ & $\mathrm{H}_{\mathrm{xs}}=2.704$ \\
\hline$d=0.646$ & $\mathrm{~d}=\quad 0.746$ & $\mathrm{~d}=1.048$ \\
\hline PORTUGAL & SPAIN & SWEDEN \\
\hline $\mathrm{H}_{\mathrm{xs}}:=13.548^{*}$ & $\mathrm{H}_{\mathrm{xs}}:=0.0144$ & $\mathrm{H}_{\mathrm{xs}}:=12.144^{*}$ \\
\hline $\mathrm{H}_{\mathrm{xs}}=4.355^{*}$ & $\mathrm{H}_{\mathrm{xs}}=3.193$ & $\mathrm{H}_{\mathrm{xs}}=14.161^{*}$ \\
\hline $\mathrm{H}_{\mathrm{xs}}=6.955^{*}$ & $\mathrm{H}_{\mathrm{xs}}=1.747$ & $\mathrm{H}_{\mathrm{xs}}=12.144^{*}$ \\
\hline $\mathrm{d}=\mathbf{0 . 5 7 7}$ & $\mathrm{d}=1.208$ & 0.816 \\
\hline
\end{tabular}

*: Statistical evidence of cointegration at the $5 \%$ level. 